\title{
Erratum to: Multiple positive solutions for time scale boundary value problems on infinite intervals
}

\author{
Xiangkui Zhao • Weigao Ge
}

Published online: 17 December 2009

(C) Springer Science+Business Media B.V. 2009

Erratum to: Acta Appl Math (2009) 106(2): 265-273

DOI 10.1007/s10440-008-9294-3

When quoting from [1] and [2] on pp. 266-267, the authors failed to cite these two papers. For the record, four whole paragraphs that were used by the authors were taken from Tisdell and Zaidi [1, p. 3505] and from Henderson and Tisdell [2, p. 111]. These sentences sketch in outline the mathematics and its motivation, but do not contain theorems.

\section{References}

1. Tisdell, C.C., Zaidi, A.: Basic qualitative and quantitative results for solutions to nonlinear, dynamic equations on time scales with an application to economic modeling. Nonlinear Anal. 68, 3504-3524 (2008)

2. Henderson, J., Tisdell, C.C.: Topological transversality and boundary value problems on time scales. J. Math. Anal. Appl. 289, 110-125 (2004)

The online version of the original article can be found under doi:10.1007/s10440-008-9294-3.

X. Zhao $(\bowtie) \cdot$ W. Ge

Department of Mathematics, Beijing Institute of Technology, Beijing 100081,

People's Republic of China

e-mail: zhaoxiangkui@126.com

X. Zhao

Applied Science School, University of Science and Technology Beijing, Beijing 100083,

People's Republic of China 